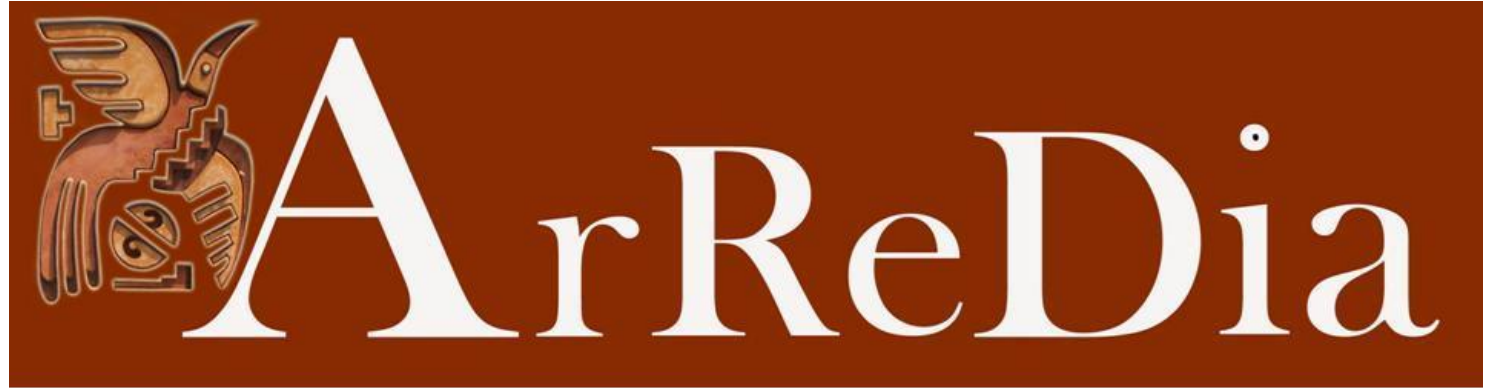

Revista da Faculdade de Comunicação, Artes e Letras / UFGD

\title{
JACK KEROUAC E O ROMANCE MODERNO: O DEVIR ESCRITOR
}

\section{Jack Kerouac and the modern novel: becoming a writer}

\author{
Samir de Carvalho ${ }^{i}$ \\ Universidade Estadual do Oeste do Paraná
}

\begin{abstract}
Resumo: O presente trabalho tem como objetivo a descrição do método de escrita de Jack Kerouac, a localização de focos de influência e o exame da importância do devir escritor na história do romance moderno. Em especial, analisa-se a nuance enquanto característica formadora de Kerouac como escritor importante na história do século XX. A partir de observações estéticas e descrição histórica do método do escritor americano, pretende-se desconstruir o mito que existe de Kerouac como artista instintivo e ingênuo e mostrar sua evolução gradativa dentro do ofício de escritor.
\end{abstract}

Palavras-chave: Jack Kerouac. Geração Beat. Literatura Americana. Devir.

\begin{abstract}
The objective of this work is to describe the writing method of Jack Kerouac, finding traces of artistic influence and analyzing the importance of the becoming of the writer for the modern novel. Especially, we inquire the nuance as a peculiar characteristic of Kerouac as an important writer in the $21^{\text {st }}$ century. Through aesthetical observations and historical descriptions of Kerouac's method, we intend to deconstruct the myth behind the idea of the naïve, wholly instinctive writer and show his gradual evolution in the writers trade.
\end{abstract}

Keywords: Jack Kerouac. Beat Generation. American Literature. Becoming.

\section{Introdução}

A tendência de leitores desavisados de esquecer a entidade do escritor como algo cambiante e do livro como uma metamorfose constante faz com que a ideia de um método de escrita se torne unívoca e estanque. Existem, na realidade pessoal de um autor, centenas de artistas que, no devir do escritor que nunca se define finalmente, se manifestam mais ou menos. A vida interior dos artistas é rica e, como mostram Morgan e Stanford (2010), é um desejo premente para alguém que possui essa riqueza que interpenetra a vida de matizes diferentes de compartilhar e multiplicar esta percepção plural. O compartilhar parece fortalecer o vínculo do próprio escritor com o que ele viveu e com o que divide.

Willer (2013) nota que, para o escritor americano Jack Kerouac, nascido em 1922 em Lowell, a literatura é também uma forma de salvação e iluminação. Na 
tentativa de escrever um romance inovador que correspondesse a suas necessidades de expressão, Kerouac compôs On the Road, concluído pela primeira vez em 1951 (publicado apenas em 2007). A novidade do estilo, devedor de diversos polos de influência que vão do Jazz a James Joyce, flanqueada pela representação gráfica e material, ofereceram ao romance uma fama quase mitológica na literatura americana. O livro fora escrito em um papel telex enrolado formando metros e metros de um parágrafo único, como um sublime automóvel silábico que viaja sintaticamente sobre uma rodovia de papel. O objetivo de Kerouac com o rolo único era o de não interromper o fluxo espontâneo de palavras e ideias todas as vezes em que terminasse uma folha, e precisasse trocá-la. Charters (2007) salienta que Jack tentava reproduzir a linguagem da mente sem disfarces linguísticos formais, e que tentou comunicar experiências não apenas através do conteúdo linguístico explícito, mas também da forma em que este conteúdo encarnava em sua prosa. Em outras palavras, não estava preocupado apenas com a temática de seus livros, mas também com sua substância poética. $\mathrm{O}$ "como dizer" tornou-se tão importante quanto "o que dizer".

A noção estética que Kerouac cunhou a partir de suas experiências e gostos pessoais formaram uma identidade de escritor. No decorrer deste artigo pretendese analisar a concepção do escritor como um devir e, mais especificamente, do devir de Jack Kerouac.

\section{O escritor, o inacabado}

Deleuze (2011) localiza a literatura no nível do devir, afirmando que, longe de estar do lado do acabamento, da finalização, posta-se do lado do inacabado, daquilo que está se fazendo e construindo. A construção sintática e literária não consiste na elaboração de um ego projetado, mas na composição de devires. Os devires são resultado de inimagináveis coisas testemunhadas pelo escritor, coisas essas que lhe fragilizam a saúde e confundem o sintoma do mundo com uma inexistente doença do escritor. A literatura é uma saúde, e um empreendimento de saúde. Esta noção é exatamente o que Mcclure (2005) percebe ao afirmar que a arte da poesia na década de 50 estava morta, o que pressupõe uma perda completa de saúde e a extinção do devir. Para ele, os artistas da geração chamada Beat Generation eram capazes de restaurar a saúde da poesia norte-americana, percebendo exemplos de reanimação literária de Artaud, Whitman, Pound ou D.H. Lawrence. O ponto de partida histórico para os esforços públicos da geração em questão foi a leitura de poemas realizada na Six Galery, em São Francisco, em 1955, após a qual Ginsberg, que lera 
seu poema Howl, recebeu de seu editor o mesmo cumprimento que Whitman recebera de Emerson anos antes.

Com a percepção de que alcançaram um ponto sem volta, Mcclure (2005) lembra que os artistas da geração Beat despertavam para uma visão nova, fugindo definitivamente da terra cinza e sem poesia. Esse êxodo das terras da ortodoxia poética da época, que eram consideradas terras de monotonia espiritual, foi exatamente o movimento que Deleuze (2011) observa como a fuga delirante do sistema dominante através do devir da linguagem. Retomando Proust, observa que a literatura é escrita numa espécie de língua estrangeira, ou seja, seu compromisso não é tanto com a obediência a uma sintaxe formal, mas com criação de uma sintaxe cujos efeitos só se aplicam dentro desse âmbito de criação. Não apenas o faz o escritor decompondo a língua materna, mas através da invenção de uma língua dentro da língua. Assim, cada escritor ataca a doença e a morte da literatura com a única ferramenta que possui: a língua. E não apenas a língua, mas sua própria língua delirante.

Assim, percebendo a dinâmica do devir, conclui-se que nunca se torna definitivamente escritor, mas se torna gradativa e permanentemente um escritor. A condição de criador de delírios e de uma língua passa por esse esgueirar-se e furtarse, numa espécie de autoconsciência fugaz. Aplicando a fórmula de Rimbaud (apud DELEUZE, 2011, p.42), em que o então adolescente escritor francês localiza o eu como sendo um outro, podemos aproximar a lógica rimbaudiana do Cogito cartesiano implicando a existência de um eu ativo, que pensa e determina e faz-se ferramenta do tempo e para o tempo e, de outro lado, um eu indeterminado (eu sou) que é pensado. Ter um aspecto do eu que determina totalmente a existência de um "eu sou" demonstra construção ininterrupta, como pressuposto para a existência sempre cambiante do eu escritor.

Dessa forma, a transformação de um homem em um escritor passa pela transmutação de sua linguagem, pela novidade de seus delírios. Mcclure (2005) testemunha a Ginsberg que a metamorfose poética empreendida com o poema Howl foi correspondente ao que acontecera com Shelley ao escrever Queen Mab, seu primeiro poema longo. A consciência do rompimento de uma barreira através da leitura do poema pressupõe uma transformação que Mcclure estende a toda a América. O devir operando no poema da Allen Ginsberg foi possível graças a superação de suas paixões e prisões individuais para se tornar um "Bardo Épico" (MCCLURE, 2005, p. 27). Um ano depois da publicação de Howl and Other Poems, On the Road seria publicado para incandescer e transformar a escrita na América, e o escritor Jack Kerouac se tornaria um ícone da geração Beat.

\section{Como alguém se torna Jack Kerouac}

Revista Arredia, Dourados, MS, Editora UFGD, v.6, n.10: 1-14, jan./jun. 2017 
Nietzsche (2007) fala do processo de formação de um artista através de gradativos aperfeiçoamentos na técnica de elaboração. Observa o efeito gerado no público que recebe o estímulo estético, e nota que a noção do devir é, aqui, faltante, pois que o receptor não apreende a obra como devir, mas como unidade artística concluída. Para ele, os artistas procuram propagar esta visão: a de que a inspiração é algo quase que divinamente oferecido. A arte torna-se instrumento, não de iluminação ou aproximação da verdade, mas retorno a estados infantis e metafísicos. Numa tentativa de explicação desses repentinos insights criativos, postula que a inspiração artística pode ser de outra forma explicada por uma repressão da expressão direta da criatividade que é liberada efusivamente mais tarde. E como resultado dessa longa repressão, tem-se ilusão de repentina necessidade e poder de revelação iluminada.

Com este pensamento em mente, lembra-se do mito que gira em torno da ideia de Jack Kerouac escrevendo On the Road em três semanas, alimentando-se de café e benzedrina, suando uma camisa atrás de outra e batendo furiosamente as teclas da máquina de escrever. Há uma preferência romântica por ver a arte de Kerouac como uma inspiração violenta, esquecendo voluntariamente seu aspecto de ofício artístico, execução técnica e metódica da poesia aplicada na prosa, princípios artísticos orientados no jazz e na fala do americano comum. Cunnel (2007) enfatiza que na imaginação cultural a imagem da elaboração frenética de On the Road em três semanas mistura-se ao baluarte idealizado de outros cânones da contracultura, como Jackson Pollock e sua pintura gestual e Charlie Parker e seu improviso saxofônico, formando uma quase intocável tríade do período pós-guerra. A diminuição de On the Road a ícone de um período e manual de uma geração, movimento este que se sente quase que como uma obrigação imposta a Kerouac (a de romantizar a execução de sua arte), acaba por ofuscar o lado diligente de Jack para com sua prosa.

A impossibilidade do romance de três semanas começa pelo fato de que Kerouac trabalhava no livro, mesmo durante suas viagens pela América e México, desde 1948 (o livro foi terminado em 1951, ano do célebre período de 21 dias). No período de três anos que se estendem de 48 a 51, Kerouac enche seus diários com pensamentos sobre sua arte composicional e escreve três proto versões de $O n$ the Road. A noção de que Jack era obcecado por encontrar uma forma de expressão não deve dar, por outro lado, a falsa ideia de que seu formalismo era tradicional. $O$ tradicionalismo da forma era por ele percebido como uma ampla cultura de censura estética e política, e o fato de a tradição obscurecer um sentimento de honestidade fez com que Kerouac buscasse algo distante da tradição morta da América. 
Seguindo, por sua parte, a cultura de inovação, inspirado em Whitman e revivendo idiossicraticamente um movimento básico da representação da América como personalidade (a marcha para o Oeste), Kerouac encontra na transformação de sua linguagem sua própria identidade, como já mencionado na noção do escritor como vítima ativa do devir. A identidade é uma transformação, um desdobramento linguístico, um parto poético interminável.

O processo de escrita de Town and City, o primeiro livro de Kerouac foi, como mostram Morgan e Stanford (2010), doloroso e difícil, permeado de momentos de loucura, insanidade e dor. A questão da forma de se expressar era questão importante para Jack desde 1945, e a busca por um método artístico que pudesse liberar sua vida interior de forma satisfatória era imprescindível para que ele alcançasse clareza pessoal no sentido de revelação do devir e de expressão para seus leitores. O escritor americano se via portador de algo que ele chamava de visão desde 1945, e talvez mesmo antes, mas reconhecidamente lhe faltava um método de projeção artística para exteriorizar essa visão sem lhe privar de sua nitidez original. Ainda Morgan e Stanford (2010) observam que, ao discutir sua arte com Ginsberg, Kerouac foi confrontado pela ideia de que toda arte é egocêntrica, apesar de afirmar que estava dedicado a sua arte e não sua arte a ele. Antes de tudo, consiste em instrumento de descoberta pessoal, o que mostra que o escritor está, primeiro de tudo, dedicado a si como não poderia deixar de ser pelo movimento do devir. Para Ginsberg (1945 apud MORGAN e STANFORD, 2010, p. 27):

Quando nos tornamos nós mesmos sacerdotes da arte nos iludimos de novo, a arte passa a ser como um gênio da lâmpada. É mais poderosa do que nós mesmos, mas apenas por nossa própria virtude ela existe e cria. Como um gênio, ela não tem vontade própria e é até mesmo meio estúpida; mas por nossa vontade ela se move para construir nossos impressionantes palácios e provê o palácio com uma consorte, o que é mais importante. $\mathrm{O}$ alto sacerdote é um adorador que cultua o gênio que outro invocou.

O fato de trabalhar por anos em seu primeiro romance mostra o quanto o método e a forma final era algo prezado por Kerouac, e confirma a suspeita de que a gênese de um escritor passa por tortuosos caminhos pessoais que se refletem em sua forma de exteriorizar sua realidade interior. E suas correspondências com Ginsberg foram intensas ferramentas de reflexão sobre método e arte, em que o poeta e amigo o encorajou constantemente a expressão direta sem o emprego de subterfúgios e símbolos literários. Os repetidos fracassos, tanto com Town and City quanto com On the Road formaram um poeta/escritor de impressionantes capacidades de metamorfose, o que pode ser facilmente notado na pluralidade dos romances de Kerouac, mesmo aqueles escritos concomitantemente. A consolidação 
de sua arte passou pela transformação e adaptação, expedições visionárias dentro de si mesmo, ajustes forçados a tendências editoriais, tragédia pessoal, paranoia nacional, morte, vida, amor, ódio, sexo, estrada, estrada, estrada.

Deleuze (2011) nota que Whitman não hesitava em localizar a escrita no nível do fragmento e, mais especificamente, diferencia a escrita americana para com a europeia através deste traço marcante que é o fragmento em detrimento da totalidade. Em segundo lugar, na América, uma certa grosseria oral e uma precipitação verbal superam a noção da construção elaborada através da convulsão da escrita. A noção do fragmento na América é diferente daquilo que pode ocorrer na Europa por sua situação cultural e geográfica.

Sua proporção física e sua riqueza cultural são protótipos da literatura que deveria ser feita no país, e toda tentativa de biografia individual de um homem americano é por extensão uma biografia coletiva. A escrita é um ato de seleção dos fragmentos e construção artística de algo como uma colcha de retalhos plural onde cenas se entrecortam e dialogam, as cenas individuais que são sempre polissêmicas. Willer (2014) enfatiza que um dos atos artísticos que construíram a colcha de retalhos de Jack Kerouac foi a coabitação artística de personagens cultos e de personagens marginalizados. Não apenas isso, mas a fragmentação em sua obra correspondeu a uma metáfora da condição do marginal que até então era desconhecida da literatura de sucesso editorial moderno. A Europa criara personagens e autores marginais, mas seu resultado editorial foi correspondente a umas poucas tiragens, enquanto a Beat Generation transformou-se em êxito de vendas.

A formação e a metamorfose pessoal e artística de Jack aqui confundem-se, pois que escreveu em profusão e construiu seu estilo enquanto viajava pela América no final da década de 40 . As transmutações constitutivas de sua literatura passaram pelo contato direto e voluntário com personagens da margem que, para o escritor, eram imbuídos de um tipo de sabedoria faltante na epistemologia e na sabedoria tradicional e formal. Kerouac descobria assim os dois traços de caráter que vimos serem marcantes na literatura americana: o fragmento e o espontâneo.

Uma das mais fortes e reconhecidas influências na obra de Kerouac, Whitman (1938) estabelece um paralelo empregado por Kerouac em sua prosa e em suas viagens muitos anos depois do texto escrito pelo primeiro. A América ganha proporções poéticas, em outras palavras, é comparado a um enorme poema a ser explorado e apreendido. A natureza poética é, ele afirma, característica do americano. E mais ainda, o americano comum é o maior representante deste espírito poético, dessa liberdade inegociável, de sua aplicação singular da fluência de uma língua. A atribuição que se espera de um grande poeta americano, como legado por Whitman, é o de encarnar a geografia, a natureza, a riqueza natural, a pluralidade e 
a grandeza de um povo em uma literatura. Encontrar a transcendência e a novidade, criatividade e caráter visionário atendendo a sede insaciável e a necessidade premente que os Estados Unidos têm de poetas e poesia e sua capacidade de produzir grandes escritores.

Há uma conexão e uma unidade de pensamento e de percepção que harmoniza a poesia com outros âmbitos de expressão nacional como a agricultura, a arte e o comércio. Emerson (2004) retoma a noção da unicidade do Homem e suas correlações formativas presentes nos ofícios. Todos eles se colocam a serviço da humanidade, do homem, e devem manter sua noção de dignidade sem dobrar-se a orientações monetárias ou formais que barrem a livre expressão de suas potencialidades. Como um dos mais importantes mentores da literatura moderna, o pensamento de Emerson tem grande peso na formação intelectual e artística da América.

Deleuze (2011) observa que, como afirmara Melville, a língua inglesa empregada pelos americanos não tem necessidade de se construir como a língua inglesa tradicional, mas de encontrar linhas de expressão próprias ao convulsionar sua manifestação cotidiana sintática. A originalidade da língua falada e escrita no país passa por uma libertação paulatina, mas certa de traços europeus. Afinal, em um país tão rico, imitar é desperdício de material. E todo esse material fragmentado deve ser caracterizado como ecossistema poético interdependente, mas sempre fragmentado em uma sintaxe convulsiva e veiculada por um instrumento do devir.

A América prenunciava o surgimento de um escritor do século XX que se aventurasse pelas estradas da América, cantava de sua chegada há anos. Com Whitman, sem dúvidas, mas também com Melville. E, como nota Willer (2014), encontra em Jack London o prenúncio e a influência para uma literatura voltada a exploração. Leitor voraz de Jack London, especialmente durante um período de contusões enquanto jogava futebol americano para a universidade de Columbia, Kerouac absorveu e deu matizes próprios para a literatura do viajante solitário. O romance de viagens, gênero que primeiramente deu visibilidade a Jack Kerouac, é expressão palpável e notória de um espírito americano já expresso anteriormente na arte. Além disso, é característica da história do romance em si.

Um romance só tem razão de ser, segundo Kundera (2009), se revela algo que só pode ser transmitido através da estrutura formal que é o romance. A filosofia ocidental, que desde os gregos se propôs a ponderar o mundo e analisá-lo como um problema a ser resolvido, paulatinamente abandonou a questão do ser do homem, assim como fez a ciência. A arte ocidental do romance se formou como uma compensação para essa lacuna deixada pela filosofia e pela ciência. $\mathrm{O}$ mundo exterior dos primeiros romances europeus, que relatavam experiências de longas 
viagens, deu lugar a viagens interiores de romances mais intimistas ou psicológicos, e eventualmente se confundiram e metamorfosearam.

Willer (2014) coloca que os textos de Kerouac atingem estrutura de existência similar àquela dos mitos no sentido de que criam heróis descomedidos, canta de suas façanhas eróticas, sua origem de nobreza (Kerouac afirmava vir de uma família de barões bretões), relata nostalgicamente suas recorrentes odisseias pela América e México. Além disso, o caráter das divindades ocidentais é, de alguma forma, repetido na conduta e no pensamento beat. $\mathrm{O}$ aspecto sempiterno caminha de mãos dadas com a transgressão e com a ausência de regras reguladoras do comportamento. Reconhecidamente, Kerouac, mas também Ginsberg, buscaram contato com sistemas de pensamento e filosofia orientais, como o budismo, no caso de Jack, o budismo e o hinduísmo, no caso de Ginsberg (que vinha de família de origem judaica). Kerouac, por sua vez, nascera em berço de fervoroso catolicismo, que o acompanhou durante toda a sua vida e que foi fonte de profundidade espiritual refletida em vários parágrafos de seus romances.

A ambiguidade dos momentos licenciosos e desregrados coabitando e rimando com temas espirituais caracteriza a obra beat como plural e livre de dicotomias de polaridades opostas. Pelo contrário, a polaridade e a ambiguidade são aproximadas, o que, seguindo a exigência de Kundera (2009), caracteriza a realização de algo que só o romance pode fazer de forma satisfatória. O fato de despolarizar o bem e o mal, faz com que eles se tornem indiscerníveis e convivam em harmonia, o que acaba por perturbar a tranquilidade maniqueísta ocidental e horrorizar a sociedade americana da época (lembremos que a beat ganhou visibilidade durante a guerra fria, em época de maniqueísmo político durante a batalha ideológica do capitalismo e socialismo).

Cunnel (2007) nota que On the Road representou uma colisão com a América tradicional, talvez não tão inovadora em conteúdo (a estrada fora tematizada anteriormente), mas em sua forma. Tanto em sua representação gráfica e material (o livro consistia em um imenso rolo de papel telex) quanto em sua inovação sintática e melódica. A violência da colisão fica evidente no fato de que o livro levou anos para ser publicado e, quando aceitaram publicá-lo, mutilaram o texto original que tinha apenas um parágrafo e nenhuma divisão capitular. A violência fica mais evidente quando revela a luta e o esforço empreendido por Kerouac para preservar sua individualidade e sua capacidade de expressar o devir em uma sociedade que tentava cercear as possibilidades de expressão artística e individuais do homem.

Willer (2014) destaca esse movimento sempre dissidente de Jack, lutando para manter sua individualidade literária e pessoal ao evitar se filiar verbal ou formalmente a qualquer movimento, preferindo a liberdade de um devir constante 
como escritor e a sabedoria do dissidente e do vagabundo. Voluntariamente abandona os estudos formais em Columbia para buscar um conhecimento que achava fosse mais válido que burocracias epistemológicas; refuta a disciplina da Marinha de Guerra e desliga-se, tendo como consequência seu internamento e diagnóstico psicótico; lamenta e esconde-se do sucesso literário, não compreendendo a aura que sua figura ganha em detrimento mesmo de sua literatura; por fim, em um movimento de defesa baseada no reacionarismo, rompe com a beat e com a contracultura que parecia dar continuidade a seu legado. Willer (2009) enfatiza que Jack empregara-se em vários trabalhos informais que lhe permitiram viajar e escrever seus romances. Trabalhou na cozinha de navios e de bares, em ferrovias como guarda-freios, em postos de gasolina, como guarda florestal no norte dos Estados Unidos. Buscava empregos que lhe permitissem liberdade burocrática e possibilidade de viagens e experiências ricas que deveriam ser o metrônomo de seu ritmo e fôlego literário.

Para Kundera (2009), a trilha percorrida pelo romance é a mesma percorrida pelos tempos modernos, ou seja, uma trilha em que a alma perde sua importância e a possibilidade de escolha se torna inexistente. Exemplifica tal sensação com a narrativa de Kafka, em "O castelo". Se o romance ocidental é inaugurado com livros de viagens, em que a personagem escolhe suas aventuras, aqui atinge uma barreira intransponível de necessidades exteriores esmagadoras corroboradas por uma burocracia monstruosa. K. tem sua ação limitada, seu espaço de ação é definido, o sistema de lógica de K. é inexistente e é ditado por uma legislação incoerente e externa. É exatamente deste intricado sistema que Kerouac busca escapar, e no qual se sente irremediavelmente preso, mesmo em sua arte, através do sucesso editorial, das expectativas sociais depositadas em sua lendária figura, das críticas literárias, etc.

A literatura e a prosa eram, para Kerouac, uma ferramenta de expressão e libertação individuais. Charters (2007) mostra que Jack se localiza na literatura americana através de sua insatisfação e tédio diante das estruturas tradicionais de construção de sentenças. Para ele, as sentenças deveriam constituir reproduções das estruturas e caminhos percorridos pela mente, em outras palavras, a forma da mente trabalhar deveria ser fielmente reproduzida no método de escrita. Isso se daria ao contrário da forma tradicional em que a mente é mascarada através de técnicas de estilo que não enaltecem nem reproduzem com liberdade o pensamento, mas que o sobrecarregam de disfarces fantasiosos desnecessários. A percepção de que não poderia se expressar daquela forma foi o que engatilhou a busca por uma voz e um método em Kerouac. A fusão tradicional de frases expressando duas ideias, utilizando uma vírgula e uma conjunção constituía uma repetição que limitava a 
capacidade de representação da frase, e este foi um dos principais pontos que Kerouac procurou superar para encontrar um nível de expressão que lhe agradasse. A exteriorização artística ideal era aquela que, por sua espontaneidade, respondia às questões de forma mais satisfatória. Nesse sentido, a literatura budista, em especial o texto "The Seven Streams of Swiftness" expressavam a importância da resposta espontânea e indiscriminada para uma perfeita compreensão da iluminação. No cristianismo, religião em que fora educado por sua mãe, católica fervorosa, encontrara confirmação no livro de Marcos, que encoraja que se conceda liberdade expressiva ao "Holy Ghost", sem premeditação consciente e planejamento daquilo que se vai falar. Além disso, para o escritor originário de Lowell, grandes artistas como Mozart e Blake eram conduzidos pela Musa quase que passivamente, entregando-lhes seus instrumentos de composição.

Aqui fica evidente outra grande contribuição do americano comum na prosa e na composição de Kerouac. Sua tentativa de superar formalidades sintáticas tradicionais na escrita, como visto, é uma forma de aproximar a escrita da forma de expressão da mente. Poder-se-ia também dizer que foi uma forma de tentar aproximar a literatura de seu berço, de sua estrutura formadora: a oralidade. Willer (2013) enfatiza que o interesse de Jack pelo vagabundo ou pelo marginal se deu por seu caráter oral: a sonoridade de sua linguagem e sua necessidade expressiva, sua pluralidade de relatos e experiências e, mais especificamente, a forma de contar tais experiências. Esperava, através disso, também reproduzir a identidade sonora de um país. Como já vimos em Whitman (1938), a identidade de um americano também é, por extensão, identidade da América.

Deleuze (2011) localiza essa relação entre homens na América em um nível afetivo chamado por Whitman de "Camaradagem". Da mesma forma que o poeta canta e une fragmentos naturais da paisagem americana nas linhas do seu poema, também o faz na relação dos homens uns com os outros através deste sentimento mais elevado e expresso na prosa e na poesia. Em nenhum outro lugar a camaradagem viril é tão expressiva quanto na América, tendo mesmo aspectos políticos e de representatividade nacional. A traição deste sentimento veio, entretanto, antes mesmo nos Estados Unidos do que no desmoronamento da camaradagem soviética em 1917. Willer (2009) mostra a amizade como sendo fundamental no movimento beat. Isso permite a interpretação de que tais artistas empreenderam, conscientemente ou não, um retorno a camaradagem no âmbito americano através da coesão dos fragmentos e a coabitação de classes sociais diferentes dentro de mesmos ambientes poéticos e estéticos. Kerouac e Neal Cassady foram companheiros de viagem, Ginsberg ajudou os autores beat (inclusive Kerouac) em seus embates editoriais, Lawrence Ferlinghetti publicou seus amigos em sua 
editora em São Francisco, Kerouac visitou Buroughs quando este morava no Marrocos. Os exemplos são diversos.

Morgan e Stanford (2010) destacam o exemplo, talvez, mais caracteristicamente literário, ao reproduzir as correspondências de Kerouac e Ginsberg desde seu encontro na universidade de Columbia em 1944, até 1963 (Kerouac viria a falecer seis anos mais tarde). Nestas, discutem o desenvolvimento de sua arte, dividem experiências artísticas e pessoais, além de compartilhares informações pessoais e de suas viagens. Tanto o livro On the Road quanto Howl são mencionados e discutidos em profusão. A vida interior e os métodos dos artistas são inseridos como partes inerentes do devir escritor que colhe os fragmentos e une os retalhos em sua espontaneidade. O centro de toda essa algaravia de vozes no tempo é chamada de camaradagem, a nível literário, mas também a nível íntimo. Willer (2009) salienta que a camaradagem alcançou níveis afetivos e mesmo sexuais. Kerouac e Neal Cassady (o herói Dean Moriarty de On the Road) compartilharam visões e quilômetros, mas também compartilharam mulheres. A amizade superou mesmo as diferenças ideológicas, já que, apesar do caráter reacionário do Kerouac no fim de vida, continuaram trocando correspondências. Esse traço fraterno faz parte da dinâmica estética da beat, onde vozes se sobrepõem dentro do romance e do poema. Para Willer (2013), Kerouac desenvolveu um romance que expõe características fundamentais do romance polifônico, como expresso por Bakhtin (1993). A dialogicidade espontânea que se fundamenta na fala do americano comum, nos fragmentos naturais e sociais da América, na sabedoria do andarilho e da estrada e na camaradagem são partes atuantes da forma estética da prosa de Kerouac. Todos estes fatores contribuíram para a formação ininterrupta de Kerouac como grande escritor americano.

\section{Conclusão estética: onde Kerouac chegou}

O fato dos romances de Kerouac dissolverem grandes polaridades em um período de grandes polaridades políticas, sociais e religiosas mostra que ele pertence a uma classe de romancistas modernos que ignoram a tentação do reducionismo em qualquer nível. Kundera (2009) define esse tipo de romance como pertencente a uma época, a do "período dos paradoxos terminais" (p.19). Para ele, o romance pertence a um mundo relativo, cheio de ambiguidades. Um universo totalitário e unívoco é uma atmosfera letal para o desenvolvimento e a evolução do romance. On the Road levou anos para ser publicado em sua forma editada e muitos anos mais para ganhar uma versão original e sem cortes, e Kerouac ainda está longe de ser unanimidade em um mundo acadêmico de regras e formalismos. Apenas um romance que respira 
e extrai seu oxigênio de uma atmosfera de liberdade e cria esse sopro de inovação pode ser considerado como participante da história do romance. A contribuição para o crescimento das possibilidades romanescas é essencial. A morte do romance consiste, não na desaparição repentina do gênero, mas no cessar de descobertas, de inovações, dando lugar a uma sucessão nauseante de repetições e repetições.

O fato de o romance estar nas mãos de uma mídia que distribui clichês faz com que a reprodução do reducionismo ganhe lar nos parágrafos e capítulos do romance moderno. Esse espírito que tenta unificar a visão da vida, do amor e dos sentimentos mais caros ao ser humano, que não aceita a pluralidade e a diferença, é contrário ao espírito do romance. A complexidade é uma das caraterísticas do gênero devido ao seu não compromisso com nenhuma verdade absoluta, um gênero em que nem Karenin nem Anna estão certos ou errados, em que não se tira proveito empreender um julgamento moral clássico do comportamento de Dean Moriarty ou Sal Paradise. Esse tipo de progresso que parece tentar arrancar respostas de todos os gêneros de coisas é um progresso que suga a vida do romance, pois este não aceita solução final para a complexidade humana.

Charters (2001) nota que as críticas empreendidas contra a Beat Generation e, mais especialmente, contra Kerouac, eram relacionadas não tanto a sua arte quanto ao comportamento que parecia estimular. A espontaneidade e a inovação estética eram reprovadas por razão da onda de seguidores que tentavam encarnar o espírito da prosa e do herói criados por Jack. A crítica literária foi tímida se comparada com a crítica social de que foram alvo os artistas da geração em questão. Entretanto, como observa Nietzsche (2007), os efeitos de um conjunto ideológico (sejam eles benéficos ou maléficos), de uma filosofia, de uma religião e, por consequência, de uma literatura, nada provam sobre sua sensatez ou qualidade. Assim, sabendo que os julgamentos e valores particulares propiciam diferentes juízos no que se refere às consequências sociais visíveis da arte de Kerouac, deve-se focar sempre uma análise naquilo que é relevante a nível literário. O que ele alcançou? Que forma sua prosa atingiu em sua maturidade e o que expressou enquanto corpo definido?

Ainda para Nietzsche (2007), grandes homens de letras passavam por gênios com mais frequência do que homens de ciência por revelarem ao público seus trabalhos completos, anulando assim a visibilidade e o pensamento do vir a ser como parte que não se pode obliterar do resultado final. Assim, o mito das três semanas em On the Road promove uma concepção mítica de Kerouac e do romance, e contribui para sua vulnerabilidade a críticos que desconhecem o processo de criação do escritor. O devir do escritor, que é a parte constituinte de seu ego sempre cambiante, das metamorfoses arquitetadas pelos delírios linguísticos constitui, como viu Deleuze (2011), um traço indelével do ofício e da personalidade do artista. Esse 
devir nunca é atingir uma forma, mas sempre encontrar no limite uma fronteira entre duas formas.

Como enfatiza Charters (2007), a pluralidade dos romances de Kerouac colabora para criar uma imagem literária cheia de desvios, delírios e devires. No âmbito de conteúdo, romances que exploram espaços físicos amplos, países diversos, personagens de relevância e representação multíplices. Ao mesmo tempo, romances que desvelam espaços geográficos limitados, poucos e misteriosos personagens, visões turvas. Histórias de amor, de confusão, de loucura, de angústia inimaginável refletidas em uma busca acompanhada pela música dos motores na estrada, pela partitura imperfeita e ilegível das placas de trânsito, as batidas dos sapatos no cascalho e dos dedos frenéticos na máquina de escrever. A oração pelo irmão morto, a poética sombria da infância, a canção pela saúde da juventude e o êxito e a glória da saúde física, a confusão do adulto perdido nas rodovias de uma prosa inconcebível para uma nação em plena guerra fria, o álcool, a dor, a morte.

A 21 de outubro de 1969, em St. Petesburg, na Florida, morre Jack Kerouac vítima de uma cirrose acarretada por sua intensidade, sua bebedeira, sua prosa. Sua sintaxe corroeu-lhe o fígado, sua poesia fez-lhe sangrar o interior. Seu parágrafo final, escrito aos 47 anos, foi o limite glorioso de um devir escritor. Do primeiro ao último romance, da busca platônica por uma resposta, da angústia, dos amores, da vida vivida e bebida gota por gota sobraram-lhe palavras, e de palavras o escritor não morre. O túmulo de Kerouac é cheio de sussurros, e todos que param para escutar são tocados. A estrada continua, estamos todos On the Road.

\section{Referências bibliográficas}

BAKHTIN, M. Questões de literatura e de estética: a teoria do romance. São Paulo: Editora Unesp/Huicitec, 1993.

CHARTERS, A. Beat Down to Your Soul. New York: Penguin Books, 2001.

CHARTERS, A. The Portable Jack Kerouac. London: Penguin Books, 2007.

CUNNELL, H. Fast This Time: Jack Kerouac and the Writing of On the Road. In: KEROUAC, J. On the Road. New York: Viking Penguin, 2007. p. 1-52.

DELEUZE, G. A Literatura e a vida. In: G. Crítica e Clínica. São Paulo: Editora 34, 2011. p. 11-17.

DELEUZE, Gilles. Sobre quarto formulas poéticas que poderiam resumir a filosofia de Kant. In: G. Crítica e Clínica. São Paulo: Editora 34, 2011. p. 40-51. 
DELEUZE, G. Whitman. In: DELEUZE, G. Crítica e Clínica. São Paulo: Editora 34, 2011. p. 76-82.

EMERSON, R.W. The American Scholar. In: R. W. Essays and Poems by Ralph Waldo Emerson. New York: Barnes \& Nobles Books, 2004. p. 50-66.

KUNDERA, M. A arte do romance. São Paulo: Companhia das letras, 2009.

MCCLURE, M. A nova visão de Blake aos Beats. Rio de Janeiro: Azougue Editorial, 2005.

MORGAN, B.; STANFORD, M. Jack Kerouac \& Allen Ginsberg: as cartas. Porto Alegre: L\&PM, 2012.

NIETZSCHE, F. Da alma dos artistas e escritores. In: F. Humano, demasiado humano. São Paulo: Editora Escala, 2007. p. 125-163.

WHITMAN, W. Preface to Leaves of Grass. In: WHITMAN, Walt, et al. The Harvard Classics: Famous Prefaces. New York: P.F. Collier \& Son Corporation, 1938. p 388-409.

WILLER, C. Os rebeldes: Geração Beat e anarquismo místico. Porto Alegre: L\&PM, 2014.

WILLER, C. Geração Beat. Porto Alegre: L\&PM, 2009.

\footnotetext{
i E-mail do autor: samir.carvalho121@gmail.com
} 